\title{
Social Media Marketing: B2B Marketing via Nano Influencers
}

\author{
Sirineni Harshitha ${ }^{1}$, Raashi Shetty ${ }^{2},{ }^{*}$ Dr. P. Swami Sairam ${ }^{3}$ \\ ${ }^{1}$ Student at Woxsen University \\ ${ }^{2}$ Student at Woxsen University \\ ${ }^{3}$ Associate Professor at Woxsen University \\ 'harshitha.sirineni_2022@woxsen.edu.in, ${ }^{2}$ raashi.shetty_2022@woxsen.edu.in, \\ 3airam.pinisetti@woxsen.edu.in
}

\begin{abstract}
The aim and objective of the authors is to explain and analyse the effect on business-to-business sector through nano influencer marketing. The authors explain about how companies can use nano-influencers for cracking a deal or selling products between two companies. Many companies do not use nano influencers for selling their brand products, but as everybody knows how important loyalty and a good engagement rate these influencers have with their customers are, one can consider and implement the same in the business as well. In this the authors have been done based on the interview method through telephonic calls, where the researchers interviewed the clients of serval reputed companies and collected their feedback on their sayings. The researchers have asked the clients several questions related to their marketing strategies, what do they think about influencer marketing and will they allow nano influencers to sell the products to other business companies. After collecting all the feedback, the researchers have analysed the responses and came up with solutions. The empirical aspect of the paper reveals that there is a strong pattern and a high probability for companies to use LinkedIn influencers in their business to expand their presence, boost overall revenue, and improve brand equity within companies.
\end{abstract}

Keywords: Influencer marketing, Nano-influencers, B2B marketing, social media, social media marketing. 


\section{Introduction}

Influencer is a person who has the ability to influence others buying decisions because of their authority, experience, status or interaction with his or her audience [1]. He or she has a dedicated audience in a specific market with whom he or she interacts often. The size of his or her niche's subject determines the size of his or her following [1]. It is important to keep in mind that these people are not just marketing tools; they are also social partnership assets with whom marketers will work to accomplish their marketing goals. As one can see, over the last decade, social media has grown rapidly in terms of importance. The usage of social media, reaching people and promoting their products through media has increased rapidly. In social media, influencers are individuals who have built a reputation for their experience and knowledge on a particular subject. They create huge followings of passionate, committed people who are paying attention to the opinions by making frequent posts on the subject on their favourite social media platforms. Brands adore social media influencers as they can create waves and persuade their fans to purchase the goods they support.

Majorly there are five types of influencers, Mega-influencers who have followers more than 1 million (majorly celebrities). These influencers are highly active, spend more time with people and engage with audience on social media due to their celebrity status [2]. Although mega-influencers have a huge following, surveys show that as the number of followers grows, so does the rate of interaction. The commitment rate for social media followers with much more than 10 million members is just 1.6 percent. Macroinfluencers have a slightly smaller audience of range 5,00,000 to $1 \mathrm{M}$. Here, the macroinfluencers can be TV actresses, celebrities, small screen celebrities, political leaders and sports person [3]. Since, these people also have a greater extent of audience to reach the brand can expect the product tag to reach a larger audience but not as much as megainfluencers. Brands would normally perceive macro-influencer content to be even more highly qualified than nano influencers or micro influencers information. This could be a perfect match for certain brands' target audiences and objectives. Mid-Tier influencers are people who have a range of $50 \mathrm{~K}$ and $500 \mathrm{~K}$. These types of influencers might not have a celebrity status but, yet they are trusted by their followers due to their content creation [4]. Brands benefit from this form of influencer's larger presence and marginally higher interaction than macro influencers or mega influencers. Each post is credible and familiar because the product is refined but not too far. Mid-tier influencers usually spent several years ascending the levels from nano-influencer to mid-tier influencer, rather than leveraging fame for a swift rise to the top. They have a lot of content development expertise and are often linked to their customers. Micro- Influencers have a smaller group of followers when compared to the above three types. Generally, a company trust these types of influencers for brand promotion as much more effective in the terms of trust and engagement. Since, micro-influencers have such a close relationship among their fans and are much more niche-focused, this is the case. Micro-influencer content is less refined than macro- or mega-influencer content, but it can sound more natural [5]. Depending on the business priorities, this could influence the level of popularity a brand has in influencer marketing. Nano- influencers have the smallest follower's count. Nanoinfluencers provide advertisers with a limited and likely narrowed scope. What marketers miss in reach; they make up for in interaction rates. It is stated that the nano influencers have the highest engagement rate with customers. The content they provide is highly authentic and are close to audience, consequently, marketers partnering with this sort of influencer should expect a special experience [6]. Nano-influencers are often more costeffective than their larger, so companies with small capital may want to start with them. 
When they develop their followers and relationships with companies, several nanoinfluencers would not even charge brands.

Influencer marketing has evolved dramatically in the field of B2B marketing, and more businesses are researching, introducing, and improving the technique. A major part of attention is to be paid on how influencer engagement rates are and the focus on quality vs quantity metrics. The purpose of this paper is to explain the approach of nano influencers in B2B marketing. It explains about the methods followed and the results obtained whether this approach is possible or not. This paper also explains about how nano influencers can be used to crack deals and sell the products in business-to-business sector.

\section{Literature Review}

To understand influencer marketing and it is functioning to yield better result from this online marketing strategy. What are the top social media platforms that an organization can invest in? Which platform has influencers with highest ROI? The objective is to understand the working of social media marketing through influencers. Since, followers place their trust on the influencers they follow, influencer marketing is the easiest way to gain potential customers and build trust among them. To establish this level of trust brands have been spending billions on influencer marketing. Globally surveyed marketers. They surveyed potential customers who are also followers, to understand the psyche of the clients. They founded that people who consult blogs, vlogs or social media are $60 \%$ of the crowd and they would consider purchasing an item endorsed by their favourite [7]. People who would buy from non-celebrity bloggers are around 30 [7]. They suggest if companies need a wider reach and are tight on budget, they should invest in macro influencers. They have noticed that researching on the influencers the company wants to invest in is a must. The content posted by them should be relevant to the message the organisation wants to spread to the audience. Instagram stands at $69 \%$ in terms of popularity, Twitter stands at $8 \%$, LinkedIn at $8 \%$, Facebook at $4 \%$ and YouTube at $4 \%$ [7]. Around $39 \%$ of companies will invest in influencers if they see a potential market. Brands spend around 32,000 when they invest on an entire campaign with a microinfluencer and spend around 39,000 on celebrities [7]. The younger employees lean more towards influencer marketing than traditional ones. Men buy much expensive products getting influenced by influencers than women. Around 83\% would purchase products marketed by influencers. $99 \%$ of the crowd have not heard of the brands or products influencers promote and hence are more intrigue [7].

The author [8] aims at creating an understanding of how social media can help B2B, B2C and B2B2C. It aims at identifying which industry uses it more. How is the usage of social media different in different organizations such as $\mathrm{B} 2 \mathrm{~B}, \mathrm{~B} 2 \mathrm{C}$ and $\mathrm{B} 2 \mathrm{~B} 2 \mathrm{C}$ ? Is there a difference in the usage of social media in the named organizations? Is there a difference in promotion in different social media platforms? Does B2B use different tactics on social media as compared to other organizations? Does the use of social media help in perceiving the effectiveness of social media influencing in different stages of customer life cycle? The objectives are to establish a relationship between effectiveness of different social media platforms and the organizations using them to promote products [8]. To understand which organization uses social media platforms for online promotions. This paper uses exploratory quantitative survey methodology and uses different analysis methods to understand how the usage of social media is different in B2B organisations. No hypothesis is constructed as they have used an exploratory approach towards this topic. The survey was conducted on 4 different types of volunteers 1) homogenous $\mathrm{B} 2 \mathrm{~B}$ 2) homogenous $\mathrm{B} 2 \mathrm{C} 3$ ) mixture of both $\mathrm{B} 2 \mathrm{~B}$ and $\mathrm{B} 2 \mathrm{C}$ and 4) B2B2C [8]. Post-hoc ANOVA was used to answer the first three research questions. 
They assumed variance to be homogenous. For establishing a relationship of importance of the platform, PLS-SEM model was used [8]. This was used keeping in mind the small groups of data in the dataset. It was noticed that there was not much difference as to which social media platform was more important to the 4 organisations they considered. B2B companies just use is less frequently and have absolute control over what goes on social media network [9]. B2B companies communicate with their clients differently. They believe in having face to face conversations. Since B2C want to have a many-tomany approach towards online marketing they much prefer social media platforms to any other means of online advertising. Homogenous B2B companies follow traditional approaches and are sceptical about social media marketing when compared to other organisations. Word of mouth plays a very important role in B2B2C organizations when compared to B2B [8].

This article [10] aims at finding out whether influencers can influence generation $\mathrm{Y}$ and $\mathrm{Z}$ into buying the products they are endorsing. If their power of influencing is worth investing in. The major question of the paper was to find out, can influencers who endorse a product can bring in the required clients and influence them to purchase it? The objective of this research is to dig deeper into consumer behaviour of generation $\mathrm{Y}$ and $\mathrm{Z}$ and undertake an empirical study of opportunities influencers can provide to a company as a marketing strategy. In this, Primary and secondary information was collected. Primary source of information was the referring to research conducted by other sources on the current ongoings of influencer marketing as a marketing strategy. Secondary source of information came from various domestic and international articles. Hyp0: The two generations do not have different preferences in SNS (Social Networking Sites). Hyp1: The two generations have different preferences in SNS (Social Networking Sites). Greater ROI is produced via video content, around $51 \%$ [10]. Around $86 \%$ of women population turn towards SNS before purchasing an item. 32\% of influencers deem Facebook as the best platform to product a product followed by Instagram at 24\% [10]. $71 \%$ of the population depend on social media for product reviews [10]. The most viewed beauty videos on YouTube were made by influencers, compared to the beauty channels by beauty brands themselves. Beauty videos have been increasing over time to over $65 \%$ every year. Around $57 \%$ of beauty brands currently use influencers to market their products and more $21 \%$ plan on following this strategy in the future. The findings of this paper are, $48 \%$ knew what "influencer" meant and $22 \%$ had heard the term but did not know who they were, $66 \%$ are ardent followers of influencers, $21 \%$ just visit their profiles in their free time and $13 \%$ do not track them on SNS [10]. According to Gen Z Instagram was favourable but according to Gen Y Facebook was the most liked.

The author [11] explains how social media works in influencing people and their behaviour and then help companies build a strategy to reach the right customer at the right place [11]. The major finding of this paper is to find does social media influence user behaviour; can this strategy be used to reach the right customers? To understand the level of trust the followers have on their influencers [11]. To understand if potential customers trust their reviews. To understand the purchase behaviour. To understand if this works on different demographics or if there is a pattern. To understand what platforms each demography of people prefer. This research uses descriptive and empirical framework and uses simple random samples. This paper created a questionnaire. Trusting influencer opinion and the gender have no significant difference [11]. Trusting influencer product reviews and the gender have no significant difference. Purchasing and the gender have no significant difference. Trusting influencer opinion and the age have no significant difference. Trusting influencer product reviews and the age have no significant difference. Purchasing and the age have no significant difference. The most popular social media 
platform is Instagram followed by Facebook and YouTube. Only 15\% have no interest in SNS [11]. Most followers are sceptical if they should place their trust on an influencer endorsing a product. Even though influencer marketing can help boost up potential customers the final purchase in may be independent of the marketing strategy.

[12] explains the insights on the strategic use of social media influencers. A study has been done with the help of the Scopus database which has concluded that most of the studies were empirical and survey methods, content analysis, experimental, or interview methods. While a couple of studies analysed what influencers can induce social change or mean for popular assessment, most of the studies focussed on the utilization of influencers as a business advertising strategy. Here, the authors named Liselot Hudders, Steffi De Jans, and Marijke De Veriman (2020) used Stem's Revised Communication Model as an advertising framework, the studies of this framework are classified into three types: source, message, and audience. The first exploration stream focussed on the points of view of influencers and correspondence experts [12]. The second characteristic talks about the substance methodologies utilized by influencers in their supported stories or posts [12]. The attractiveness of influencer marketing and the effectiveness of its funded advice was the subject of the third stream of research [12]. The openness of this clandestine marketing plan was an issue in many types of research in the rice results.

[13] explains to see how nano influencers affect Instagram as they're used for influencer marketing for a small restaurant in Dublin [13]. The study aims to understand how nanoinfluencers affect Instagram and how they can be used for marketing purposes. The study also aims the understanding and relation the customers with influencers. It also explains their intention to buy goods and services from businesses. The author used a hybrid technique approach that included both mixed (qualitative and quantitative) methods. The analysis placed a large restaurant in Dublin and several nano-influencers have been used to conduct the descriptive study. The testing was performed in real-time and see how the nano-influencers affected the hotel's revenues. The research method used a sample to look at different aspects of content marketing, the social networking software Instagram, as well as the correlation among confidence and purchase intent using the Bruns-Siddiqui model. The results led to the suggestion that nano-influencers have a favourable impact on dining revenue as well as customer loyalty between the supporters. According to the results of a survey, Instagram is among the most common social media platforms by users. It was also discovered which Generations $\mathrm{Y}$ and $\mathrm{Z}$ are the most regular members of social networking sites and web video. This innovative review thesis on a small hotel in Dublin is the first of its kind in Ireland, utilizing real-time nano-influencers [13].

\section{Research Question and Hypothesis}

The main aim of this research is to understand if B2B companies can see themselves updating their age-old marketing strategy to something that is the current trend that is here to stay, influencer marketing. The researchers wanted to establish if they could sell the idea of nano influencer marketing, next best thing, be used in the world of Automobile and IT. The research questions were as follows taking the sample (Automobile and IT) from a population of $\mathrm{B} 2 \mathrm{~B}$ industries:

1. For B2B Automobile industries:

a. Can nano influencer marketing be used to market products in Automobile industries?

b. If yes, on which social media platform?

\section{For B2B IT industries:}



a. Can nano influencer marketing be used to market products in IT industries?
b. If yes, on which social media platform?

Keeping the above questions in mind the researchers derived the below mentioned hypothesis:

Hypothesis One: Nano influencer marketing can potentially be used in promoting B2B products (Automobile).

Hypothesis Two: Nano influencer marketing cannot be used in promoting B2B products (Automobile).

The alternate hypothesis (Hypothesis One) supporting their research that nano influencer can play a role in the marketing of products of B2B industries, the Automobile sector.

The null hypothesis (Hypothesis Two) contradicting their research that nano influencer can play a role in the marketing of products of $\mathrm{B} 2 \mathrm{~B}$ industries, the Automobile sector.

Hypothesis One: Nano influencer marketing can potentially be used in promoting B2B products (IT).

Hypothesis Two: Nano influencer marketing cannot be used in promoting B2B products (IT).

The alternate hypothesis (Hypothesis One) supporting their research those nano influencers can play a role in the marketing of products of B2B industries, the IT sector.

The null hypothesis (Hypothesis Two) contradicting their research those nano influencers can play a role in the marketing of products of $\mathrm{B} 2 \mathrm{~B}$ industries, the IT sector.

If the alternate hypothesis is accepted, which is the most favourable social media site that has nano influencers targeting the required audience or rather clientele they would set out to invest in.

\section{Methodology and Analysis}

The researchers have narrowed down on two B2B industries, as samples of the vast population of B2B industries.

The research aimed at Automobile sector and IT as a B2B industry and an interview of 3 people from each of the mentioned sectors was taken. These were people working at the top tier of their companies in the field of marketing. The interview was conducted over phone and the questionnaire was dynamic based on the direction the conversation was heading. This dynamic questionnaire gave us an insight on the mindset of these executives when it came to influencer marketing as a whole and the use of nano influencers in promoting their products to other companies which could be potential customers in the future.

Even though the questionnaire was dynamic, the researchers had a set of questions in mind that they needed answers to. Firstly, did he or she, as a marketing executive, ever come across the term "influencer marketing". If yes, they were asked to brief us on the concept so the researchers could gauge their understanding of the topic. If no, the researchers would then brief them on the same to make them understand their objective behind the research being conducted. They were then asked if they were familiar with the 
concept of nano influencers. If yes, they were asked to brief us on the concept. If no, the researchers explained the concept to them.

The researchers wanted to understand their current marketing strategy to see if there were any chances of nano influencers as a marketing strategy to be use in their respective companies. Out of the 6 participants, 3 refrained from sharing the information as they felt they would be violating the company policies by letting out the trade secrets. The 3 participants who were willing to share their companies marketing strategy narrated it to us. The common thing the researchers noticed amongst the 3 participants was that they all used traditional marketing strategies, or rather their companies were comfortable following the same old strategy that worked for them ages ago. What was surprising was that many of these companies were not familiar with the newest and most used marketing strategy in the current day and age.

Out of the three executives who were interviewed as representatives of the Automobile industries, only 1 had prior knowledge about the concept of influencer marketing. The 2 who were unaware were briefed about whole concept and their main objective behind thinking nano influencers would be a great fit to promote Automobile products to other potential customers. The researchers were told about the general marketing strategy in any Automobile industry by one of the executives, they were told that Automobile industries in general followed any or all the below mentioned marketing strategies:

1. Participating in global forums or exhibitions to promote their products to potential customers.

2. Conducting meets where the target audience is invited to participate to understand the products and its functioning.

3. By engaging with third party vendors who act as a middleman between the two businesses and in return gets a cut of the profit if the sale is initiated and a relationship is built between the company and the potential customer.

On listening to the third marketing strategy, the researchers asked him if his company would ever fathom moving towards nano influencers to act as a bridge between the two establishments instead of employing a third-party vendor. The researchers explained to him how this could be beneficial as the outreach to genuine potential customers via a nano influencer would be far greater than that of a third-party vendor who could hook them up with a limited count of potential customers. He was asked if his company would ever be opened to adopt nano influencer marketing if in the future. To which he replied, if it could potentially increase their sales performance and if it is a tool that they could use, they would probably use it in the future. To this the researchers counter questioned by asking him the social media platform that would be the right fit to promote their products via nano influencers. To which he replied, twitter may not so useful because they would have to display the technologies imbibed in their products and narrate its usefulness to sell them, and twitter could not act as a medium to do so. Any social media platform wherein the videos demonstrating the working of their product can be displayed would be the most apt social media platform. The researchers suggested platforms like Instagram and LinkedIn. To which he replied that LinkedIn is a professional set up and his company would rather invest in an influencer on such a platform.

The other executives told us that they would not budge from their traditional marketing strategy as its works for them and venturing to other platforms would be a risk they cannot take. 
Moving on to the IT industry, upon interviewing an executive the researchers came to know that his company currently uses the help of marketing agencies, that help take their brand messaging across medias and to global 2000 clients. They use social media extensively to market and use influencers who are IT analysts, basically employing advisory companies who produce analytical reports about IT services to able to reach out to potential clients through them. They take the help of mega influencers to do so because of the size and the global outreach of the firm. They collaborate with such firms, who have a major social media footprint, to ensure the companies message and service offerings is well understood and properly represented in the reports. He was then informed by us that according to reports mega influencers have the highest chances of having fake followers and lower engagement rate and asked if his company was aware of the same. To which he replied that they choose influencers who have at least $80 \%$ genuine followers and potential clients. The researchers asked him if his company would rather invest in nano influencer, who are way cheaper and have a higher engagement value as compared to mega influencers, to promote their products in the future. He responded by saying that they choose to do that sometime in the future and said that his company believes nano influencers today primarily operate within the B2C model and his company is yet to see the maturation of nano influencer being able to provide the kind of outcome that they expect in B2B models. At this point they are not convinced that there may be sufficient nano influencers in their services segment. When given an example of SAP, a company that used nano and micro influencers who were freelancing independent consultants for big firms that SAP was aiming to target to promote their products, he then showed some interest towards the same and felt it was worth a look to understand what it is and if it is applicable to them. If they ever did use such influencers, they would move towards the mavens on LinkedIn as most of their clients typically operate from and engage with his company on this platform.

Another executive felt elated by the idea of using influencers, especially nano influencers, to market their products provided it was cost effective and bought down their existing marketing and advertising cost.

The third executive was apprehensive about the whole concept and felt it was a fad that might fade over a period, and they cannot afford to change their marketing strategy every time a new strategy comes in town, as building a strategy takes a lot of trial and errors and investment to finally flourish and be fruitful and to step away from an already successful model would not work in their favour.

\section{Future Scope}

In the future, many more such executives can be interviewed to get a wider sample size to understand how much of knowledge transfer is required to educate them on this new trend that is here to stay. The research can be expanded to other B2B business such as pharma, technology services and banking and shed light on whether nano influencers can be used in promoting the respective products. If these industries chose to venture into nano influencer marketing, which platform would they most likely to be attracted towards? To understand which platform other than LinkedIn can help reach the right target audience. One could try to dig deeper to understand if these influencers will ever have a future in the B2B market or if they will remain a fad that not many such industries understand.

\section{Conclusion}

From top tier executives whose interviews were taken to represent their respective fields, one thing that was very obviously noticed was their lack of knowledge on the topic 
"influencer marketing" let alone "nano influencer marketing". Once, they were briefed on their research objective and the topic in general only one executive in the automobile sector seemed to show some interest in nano influencers as a mode to spread product awareness to potential clients. The others chose to stick to the traditional marketing strategies. Thus, accepting the null hypothesis $(\mathrm{H} 1)$ that nano influencers may not be the right fit to promote $\mathrm{B} 2 \mathrm{~B}$ products in the automobile sector. Whereas, in the IT sector two executives seemed to show an inclination, even though slight, to invest in nano influencers in the future. Thus, accepting the alternate hypothesis $(\mathrm{H} 2)$ that nano influencers may be the right fit to promote B2B products. Educating B2B companies with examples or concrete proof of its fruition may help boost the engaging of nano influencers with $\mathrm{B} 2 \mathrm{~B}$ companies at whole.

The companies or executives that do find the concept of nano influencers as a marketing strategy intriguing felt LinkedIn would be the perfect social media platform to promote their products as it is a social media platform for professionals who are looking to build a relationship with other professionals and their potential customer were likely to visit this social media site to get updates on latest technology and services. With over 740 million active users in the year 2020, LinkedIn may act as the hub for B2B business looking to promote their products online via nano influencers. 


\section{References:}

[1] "What is an Influencer? - Social Media Influencers Defined [Updated 2021]." https://influencermarketinghub.com/what-is-an-influencer/ (accessed Mar. 23, 2021).

[2] A. Narassiguin and S. Sargent, "Data Science for Influencer Marketing: feature processing and quantitative analysis," May 2019, Accessed: Jul. 02, 2021.

[Online]. Available: http://arxiv.org/abs/1906.05911.

[3] R. Alassani and J. Göretz, "Product placements by micro and macro influencers on instagram," in Lecture Notes in Computer Science (including subseries Lecture Notes in Artificial Intelligence and Lecture Notes in Bioinformatics), Jul. 2019, vol. 11579 LNCS, pp. 251-267, doi: 10.1007/978-3-030-21905-5_20.

[4] E. Moriuchi, "Influencer Marketing," in Cross-Cultural Social Media Marketing: Bridging Across Cultural Differences, Emerald Publishing Limited, 2021, pp. 4553.

[5] D. P. Dolowitz, R. Plugaru, and S. Saurugger, "The process of transfer: The microinfluences of power, time and learning," Public Policy Adm., Feb. 2019, doi: $10.1177 / 0952076718822714$.

[6] S. Ramadanty and Y. Safitri, "Social Media Influencers Involvement in the Digital Campaign in Indonesia," in Proceedings of 2019 International Conference on Information Management and Technology, ICIMTech 2019, Aug. 2019, pp. 48-52, doi: 10.1109/ICIMTech.2019.8843732.

[7] “(PDF) The Ultimate Guide to Influencer Marketing in 2019." https://www.researchgate.net/publication/340934984_The_Ultimate_Guide_to_Inf luencer_Marketing_in_2019 (accessed Apr. 15, 2021).

[8] S. Iankova, I. Davies, C. Archer-Brown, B. Marder, and A. Yau, "A comparison of social media marketing between B2B, B2C and mixed business models," Ind.

Mark. Manag., vol. 81, pp. 169-179, Aug. 2019, doi:

10.1016/j.indmarman.2018.01.001.

[9] R. Brennan and R. Croft, "The use of social media in B2B marketing and branding: An exploratory study," J. Cust. Behav., vol. 11, no. 2, pp. 101-115, Oct. 2012, doi: 10.1362/147539212x13420906144552.

[10] “(PDF) Influencer marketing as a modern phenomenon creating a new frontier of virtual opportunities."

https://www.researchgate.net/publication/329247338_Influencer_marketing_as_a_ modern_phenomenon_creating_a_new_frontier_of_virtual_opportunities (accessed Mar. 28, 2021).

[11] M. A. Nidamarthy, "Influencer Marketing: Reaching the Right Person at the Right 
Place," 2020.

[12] L. Hudders, S. De Jans, and M. De Veirman, "The commercialization of social media stars: a literature review and conceptual framework on the strategic use of social media influencers," Int. J. Advert., 2020, doi: 10.1080/02650487.2020.1836925.

[13] P. Hublikar, "The Study Of The Effect Of The Internet Influencers OnSmall Scale Restaurants In Dublin Using Instagram,” 2020. 